\title{
White (but Not Black) Americans Continue to See Racism as a Zero-Sum Game; White Conservatives (but Not Moderates or Liberals) See Themselves as Losing
}

\author{
Raea Rasmussen ${ }^{1}$, David E. Levari ${ }^{2}$, Muna Akhtar ${ }^{1}$, Chelsea S. Crittle ${ }^{1}$, Megan Gately ${ }^{3}$, \\ Jeremy Pagan ${ }^{1}$, Andrea Brennen ${ }^{1}$, Dylan Cashman ${ }^{4}$, Alia N. Wulff ${ }^{1}$, \\ Michael I. Norton ${ }^{2}$, Samuel R. Sommers ${ }^{1}$, and Heather L. Urry ${ }^{1}$ \\ ${ }^{1}$ Department of Psychology, Tufts University \\ ${ }^{2}$ Negotiation, Organizations \& Markets, Harvard Business School \\ ${ }^{3}$ Geriatric Research Education and Clinical Center, VA Bedford Health Care System \\ ${ }^{4}$ Department of Computer Science, Tufts University
}

\begin{abstract}
Author Note
We preregistered our studies on the Open Science Framework. The preregistration for the initial small-scale study in April 2018 is available at https://osf.io/bgc94. The preregistration for the large-scale study in October 2019 is available at https://osf.io/3jye4. We have no known conflicts of interest to disclose. We received funding from Harvard Business School and the Faculty Research Awards Committee in the School of Arts and Sciences at Tufts University. See our supplemental materials for author contributions according to the Contributor Roles Taxonomy. We used the Tufts University High Performance Compute Cluster (https://it.tufts.edu/high-performance-computing) for some analyses reported in this paper.

Correspondence concerning this article should be addressed to Heather L. Urry, Tufts University, 490 Boston Avenue, Medford, MA 02155. Email: heather.urry@tufts.edu
\end{abstract}

Accepted for publication in Perspectives on Psychological Science, January 8, 2022. This is PsyArXiv, version 1. Copyright held by the Authors. Reuse is restricted to non-commercial and no derivative uses. 


\begin{abstract}
Norton and Sommers (2011) assessed Black and White Americans' perceptions of anti-Black and anti-White bias across the previous six decades - from the 1950s to the 2000s. They presented two key findings: White (but not Black) respondents perceived decreases in anti-Black bias to be associated with increases in anti-White bias, signaling the perception that racism is a zero-sum game; White respondents rated anti-White bias as more pronounced than anti-Black bias in the 2000s, signaling the perception that they were losing the zero-sum game. We collected new data to examine whether the key findings would be evident nearly a decade later, and whether political ideology would moderate perceptions. Liberal, moderate, and conservative White (but not Black) Americans alike believed that racism is a zero-sum game. Liberal White Americans saw racism as a zero-sum game they were winning by a lot, moderate White Americans saw it as a game they were winning by only a little, and conservative White Americans saw it as a game they were losing. This work has clear implications for public policy and behavioral science, and lays the groundwork for future research that examines to what extent racial differences in perceptions of racism by political ideology are changing over time.
\end{abstract}

Keywords: discrimination, racism, United States, conservative, liberal, zero-sum game 


\section{White (but Not Black) Americans Continue to See Racism as a Zero-Sum Game; White Conservatives (but Not Moderates or Liberals) See Themselves as Losing}

Barack Obama, a multiracial (Black/White) Democrat, was elected president of the United States in 2008. Many claimed that Obama's election heralded the arrival of a "postracial" society in America (e.g., NPR news piece titled, "A New, 'Post-Racial' Political Era in America" [Schorr, 2008]) despite Black Americans experiencing worse outcomes than White Americans in domains ranging from education and socioeconomic outcomes to police treatment and health (e.g., APM Research Lab, 2020; EdBuild, 2019; Edwards et al., 2019; McIntosh et al., 2020). It was in this context that Norton and Sommers (2011) surveyed a national sample of Black and White Americans to assess their perceptions of anti-Black and anti-White bias across the previous six decades - from the 1950 s to the 2000s. They presented two key findings: White (but not Black) respondents perceived racism as a zero-sum game in which decreases in anti-Black bias were associated with increases in anti-White bias; White respondents rated anti-White bias as more pronounced than anti-Black bias in the 2000s, suggesting they thought the zero-sum game was one they were losing.

Subsequent research has corroborated this zero-sum view. White Americans consistently underestimate the Black-White wealth gap (Kraus et al., 2020), and tend to identify perceived gains by Black people as a threat to their status (Dover et al., 2016). In fact, many White people see themselves as members of an oppressed racial group (King, 2015). In addition, when growing racial diversity is highlighted, White people tend to predict that discrimination against White people will increase in the future while discrimination against minorities will decrease (Craig \& Richeson, 2017). 
Five years after Norton and Sommers (2011) documented zero-sum perceptions of bias in White Americans, Donald Trump, a White Republican, was elected president. Trump promised to fight for the "forgotten Americans" (Cowie, 2016), primarily conservative White voters who experienced economic stress following the Great Recession from 2007 to 2009, and felt disempowered by the growing representation of minority groups (Abramowitz \& McCoy, 2019; Blackall, 2020). Trump's election victory suggests that many White Americans (and White conservatives in particular) still feel disadvantaged.

Importantly, political polarization in racial attitudes may be changing over time. For example, the Republican presidential candidate was more strongly associated with racial resentment in 2016, when Trump was elected, compared to both 2008 and 2012, when Obama was elected (Tesler, 2016). More broadly, according to Pew Research Center (2017), since about 2010, the proportion of Democrats who say that racial discrimination is the reason why many Black people cannot get ahead has increased while the proportion of Republicans who say this has remained steady. Similarly, nationally representative polling indicates "widening partisan gaps in perceptions of discrimination against many groups” (Pew Research Center, 2019).

In the wake of the shift from the presidential administration of Obama to that of Trump, and evidence of increasing political polarization in attitudes about racial discrimination in the United States, we replicated Norton and Sommers' (2011) method with the goal of examining whether the two key findings from that paper were still evident almost a decade later in new participants: Do White (but not Black) Americans continue to view racism as zero-sum, whereby gains for Black people necessarily come at the expense of White people? And, do White Americans continue to believe that racism against White people is now more pronounced than racism against Black people? We also introduced a new variable not included by Norton and 
Sommers (2011), respondents' political attitudes. This allowed us to see how endorsing liberal, moderate, or conservative political ideology moderates White American views of racism as a zero-sum game, and the extent to which they believe White people are winning or losing. We conducted two studies. ${ }^{1}$ The first was an initial, small-scale replication focusing on White participants recruited from Amazon Mechanical Turk $(N=235)$ in April 2018. We present the method and results of the small-scale replication in supplemental materials.

The second was a large-scale study in October 2019 presented below. For the large-scale study, we recruited 4,000 participants via a Qualtrics panel (2,000 Black participants and 2,000 White participants, otherwise representative of the United States population with respect to age, gender, and education). ${ }^{2}$ After preregistered exclusions, ${ }^{3}$ the final sample consisted of 3,191 participants. We present sample characteristics (age, gender, education level, and political

\footnotetext{
${ }^{1}$ We report how we determined our sample size, and all data exclusions, manipulations, and measures in the studies in this manuscript and our supplemental materials. In addition to the variables described in the main text, participants completed exploratory measures of political party affiliation, approval of Donald Trump (October 2019 only), gender, perceived socioeconomic status (October 2019 only), effort, and attention. The studies were approved by the Social, Behavioral, and Educational Research Institutional Review Board at Tufts University. The preregistration for the initial small-scale study in April 2018 is available at https://osf.io/bgc94; participants completed it as the third of three studies in the survey. The preregistration for the large-scale study in October 2019 is available at https://osf.io/3jye4; although we originally intended to bundle it with other studies, participants completed the large-scale study as the only study in the survey. Unless noted otherwise, we followed our preregistered confirmatory analysis plans.

${ }^{2}$ Black participants in our sample were younger and less educated than the White participants, as in Norton and Sommers (2011). In addition, proportionally more Black than White Americans in our sample were women. Because the gender imbalance was particularly striking (see Table 1), we addressed it with exploratory analyses that we summarize in a subsequent footnote.

${ }^{3}$ We preregistered the decision to include in analyses only participants who identified their race/ethnicity as Black or White and, thus, excluded those whose race/ethnicity was coded as "Other" $(n=333)$. We also noted in our preregistration that participants with missing observations would be excluded automatically from our analyses due to listwise deletion of missing cases. We excluded participants with missing observations for the following variables: bias ratings $(n=254)$, ideology $(n=364)$, and education $(n=13)$. Finally, some participants reported being younger than 18 years of age $(n=17)$; we made the post hoc decision to exclude them because we planned to study adults ages 18 years and older. With exclusions, the smallest cell size defined by the cross between participant race and political ideology between-subjects factors was $n=286$ (Black conservatives). With a minimum of 286 participants in each group, we achieved at least $80 \%$ power to detect small true two-group differences of Cohen's $d=0.23$ or larger, and within-group bivariate correlations of $r=.16$ or larger. Thus, statistical power was adequate.
} 
ideology by race/ethnicity) in Table 1. Materials, data, and code are available at https://osf.io/4hbrg.

Table 1. Sample characteristics, October 2019.

\begin{tabular}{lccc}
\hline & Total & Black & White \\
& $N=3,191$ & $n=1,518$ & $n=1,673$ \\
\hline Age $M(S D)$ in years & $46.7( \pm 16.8)$ & $41.4( \pm 16.1)$ & $51.4( \pm 16.1)$ \\
Gender & & & \\
Man & $1,578(49.5 \%)$ & $366(24.1 \%)$ & $1,212(72.4 \%)$ \\
Nonbinary & $3(0.1 \%)$ & $2(0.1 \%)$ & $1(0.1 \%)$ \\
Woman & $1,557(48.8 \%)$ & $1,119(73.7 \%)$ & $438(26.2 \%)$ \\
Declined/Other & $53(1.7 \%)$ & $31(2.0 \%)$ & $22(1.3 \%)$ \\
Education Level & & & \\
Some high school & $140(4.4 \%)$ & $57(3.8 \%)$ & $83(5.0 \%)$ \\
High school graduate & $1,012(31.7 \%)$ & $405(26.7 \%)$ & $607(36.3 \%)$ \\
Some college & $784(24.6 \%)$ & $508(33.5 \%)$ & $276(16.5 \%)$ \\
College graduate & $722(22.6 \%)$ & $371(24.4 \%)$ & $351(21.0 \%)$ \\
Some graduate school & $92(2.9 \%)$ & $44(2.9 \%)$ & $48(2.9 \%)$ \\
Graduate school degree & $441(13.8 \%)$ & $133(8.8 \%)$ & $308(18.4 \%)$ \\
Political Ideology & & & \\
Conservative & $1,000(31.3 \%)$ & $286(18.8 \%)$ & $714(42.7 \%)$ \\
Moderate & $1,069(33.5 \%)$ & $572(37.7 \%)$ & $497(29.7 \%)$ \\
Liberal & $1,122(35.2 \%)$ & $660(43.5 \%)$ & $462(27.6 \%)$ \\
\hline
\end{tabular}

We used a 2 [Participant race: Black, White) X 2 [Target race: Black, White] $\times 7$ [Decade: 1950s, 1960s, 1970s, 1980s, 1990s, 2000s, 2010s] $\times 3$ [Participant political ideology: liberal, moderate, conservative] mixed factorial design to evaluate perceptions of anti-Black and anti-White bias. Participant race and political ideology were between-subjects participant variables; target race and decade were within-subjects manipulated variables. Participants indicated to what extent they thought Black and White Americans, in counterbalanced order, were the target of discrimination $(1=$ not at all to $10=$ very $m u c h)$ in each of the past seven 
decades. After completing these perceived bias measures, participants reported their political ideology ${ }^{4}$, race, education, and age. We graph results from Norton and Sommers (2011) and the current sample in Figure 1.

${ }^{4}$ Participants indicated their political ideology on a scale from 1 (extremely liberal) to 7 (extremely conservative). Participants who responded 1 (extremely liberal), 2 (liberal), or 3 (slightly liberal) were coded as "liberal." Participants who responded 4 (moderate/middle of the road) were coded as "moderate." Participants who responded 5 (slightly conservative), 6 (conservative), or 7 (extremely conservative) were coded as "conservative." 
Norton \& Sommers (2011)

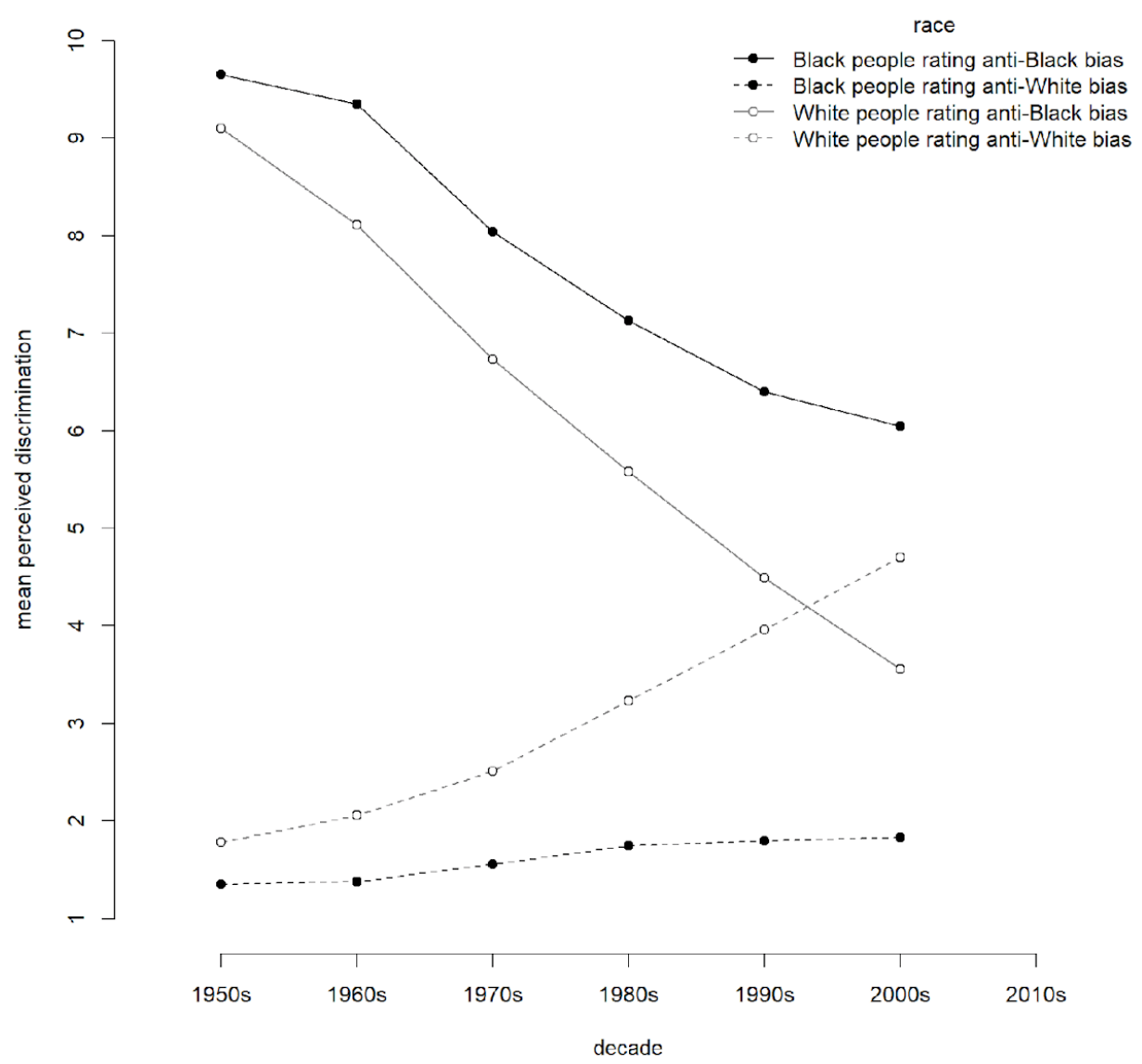

Current Sample (October 2019)
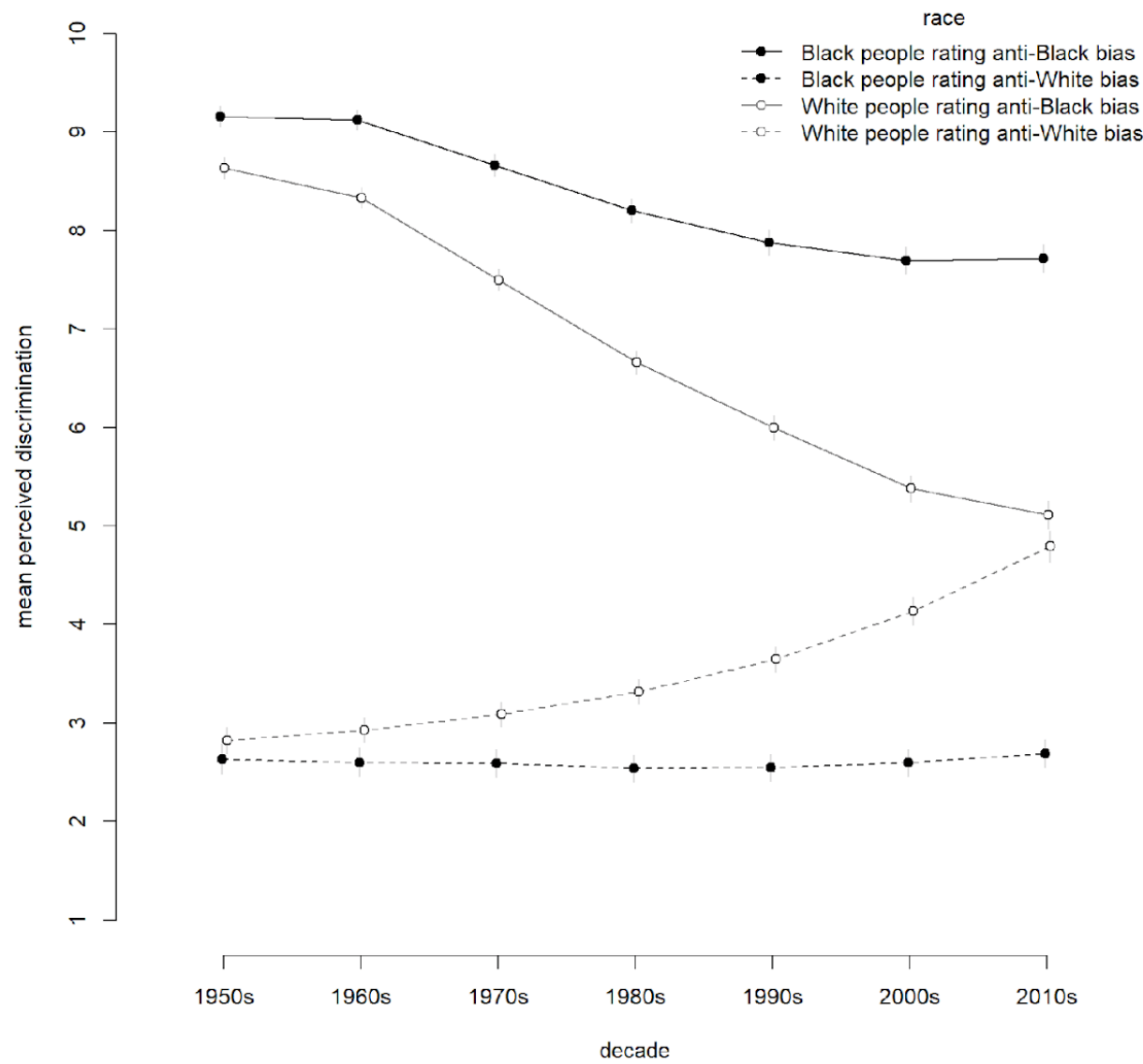

Figure 1. Discrimination against Black targets (solid lines) and White targets (dashed lines) perceived by Black participants (black lines with filled black circles) and White participants (gray lines with empty gray circles) by decade. The panel on the left shows results from Norton and Sommers (2011); there are no values for the 2010s because participants did not rate discrimination in that decade. The panel on the right shows our results from October 2019; error bars reflect 95\% confidence intervals. 


\section{Do White (but Not Black) Americans Continue to Perceive Racism as a Zero-Sum Game?}

Yes.

As shown in Figure 1 on the right and consistent with Norton and Sommers (2011), White Americans in 2019 believed that gains for Black people necessarily come at the expense of losses for White people. Specifically, White participants believed that anti-Black bias decreased steeply from the 1950 s to the 2010 s and that anti-White bias increased nearly as steeply from the 1950s to the 2010s. Black participants believed that anti-Black bias decreased modestly from the 1950 s to the 2010 s but that anti-White bias was steadily low from the 1950 s to the $2010 \mathrm{~s} .^{5}$

The difference between anti-Black and anti-White bias was consistently larger for Black participants than for White participants. Black participants endorsed a very large anti-Black versus anti-White difference in the 1950s, Hedges' $g=2.57,95 \% \mathrm{CI}[2.41,2.74]$, that was still quite large in the 2010s, Hedges' $g=1.81,95 \% \mathrm{CI}[1.69,1.92] .{ }^{6}$ White participants, on the other hand, endorsed a very large difference in the 1950s, Hedges' $g=2.32,95 \% \mathrm{CI}[2.18,2.46]$, that shrank to a negligible difference in the 2010s, Hedges' $g=0.10,95 \% \mathrm{CI}[0.03,0.17]$.

Ratings of perceived bias against Black and White Americans were negatively associated within each decade for White but not Black participants. ${ }^{7}$ For White participants, higher scores

\footnotetext{
${ }^{5}$ We used the afex package (Singmann et al., 2020) to run analyses of variance and the papaja package (Aust \& Barth, 2020) to generate figures, ANOVA tables, and APA-formatted statistics in R. The pattern in Figure 1 was supported by a statistically significant interaction between participant race, target race, and decade in the current sample. See Supplementary Table S4 for results of the confirmatory analysis of variance.

${ }^{6}$ We used the effsize package (Torchiano, 2020) in R to calculate Hedges' $g$. Hedges' $g$ is a standardized measure of effect size that is interpreted similarly to Cohen's $d$.

${ }^{7}$ We conducted a linear mixed-effects regression model using the lme4 package (Bates, et al., 2015) in R to determine whether participant race moderated associations between anti-Black and anti-White bias. The criterion variable was anti-White bias with a random intercept for participants. Predictors were anti-Black bias, participant race, and decade. We also modeled age, education, and target race counterbalance order as covariates whose effects could vary by decade. The analysis revealed that the association between perceived anti-Black bias and anti-White bias depended on participant race, as captured by the two-way interaction term, $b=0.05,95 \% \mathrm{CI}[0.04,0.07], t=$
} 
for anti-Black bias were modestly associated with lower scores for anti-White bias from the $1950 \mathrm{~s}, b=-0.08,95 \% \mathrm{CI}[-0.12,-0.05]$, to the $1980 \mathrm{~s}, b=-0.05,95 \% \mathrm{CI}[-0.08,-0.02]$. The magnitude of this association increased from the $1990 \mathrm{~s}, b=-0.10,95 \% \mathrm{CI}[-0.13,-0.07]$, to the $2000 \mathrm{~s}, b=-0.17,95 \% \mathrm{CI}[-0.2,-0.14]$, and reached a peak in the $2010 \mathrm{~s}, b=-0.22,95 \% \mathrm{CI}[-0.24$, -0.19]. For Black participants, the associations between anti-Black bias and anti-White bias hovered near zero in all decades. For example, the association was, $b=-0.03,95 \% \mathrm{CI}[-0.07$, $0.01]$, in the $1950 \mathrm{~s}$, and $b=0.01,95 \% \mathrm{CI}[-0.02,0.03]$, in the $2010 \mathrm{~s}$.

Finally, among White participants, the association between perceived change in antiBlack bias from 1950 to 2010 (2010s minus 1950s) and perceived change in anti-White bias over the same time frame differed by participant race. ${ }^{8}$ For White participants, larger perceived decreases in anti-Black bias were associated with larger perceived increases in anti-White bias, $b=-0.23,95 \% \mathrm{CI}[-0.27,-0.18]$. For Black participants, the association between change in anti-Black bias and change in anti-White bias was near zero, $b=0.02,95 \% \mathrm{CI}[-0.03,0.07]$. Collectively, these results demonstrate that, in 2019, White people continued to view racism as a zero-sum game, as they did in 2011. But, unlike in the work of Norton and Sommers (2011), White people saw the zero-sum game as one they were winning by a little, not losing. As in our small-scale study in April 2018, a fuller understanding required considering political ideology as a moderator.

$8.26, p<.001$. This two-way interaction was moderated by decade as a quadratic trend, $b=0.03,95 \% \mathrm{CI}[0.01$, $0.05], t=3.08, p=.002$. $P$ values are based on Satterthwaite's method. (We originally preregistered an ordinary least squares model with effect coding of decade. However, the repeated measure across decades, an ordinal factor, made linear mixed-effects regression and polynomial coding more suitable.)

${ }^{8} \mathrm{We}$ ran an ordinary least squares linear regression in which the criterion variable was change in ratings of antiWhite bias (2010s - 1950s). Predictors were change in ratings of anti-Black bias and participant race. We also modeled age, education, and target race counterbalance order as covariates. The analysis revealed a significant interaction between change in anti-Black bias and participant race, $b=0.12,95 \%$ CI $[0.09,0.16], t(3184)=7.27, p<$ .001 . 
liberal

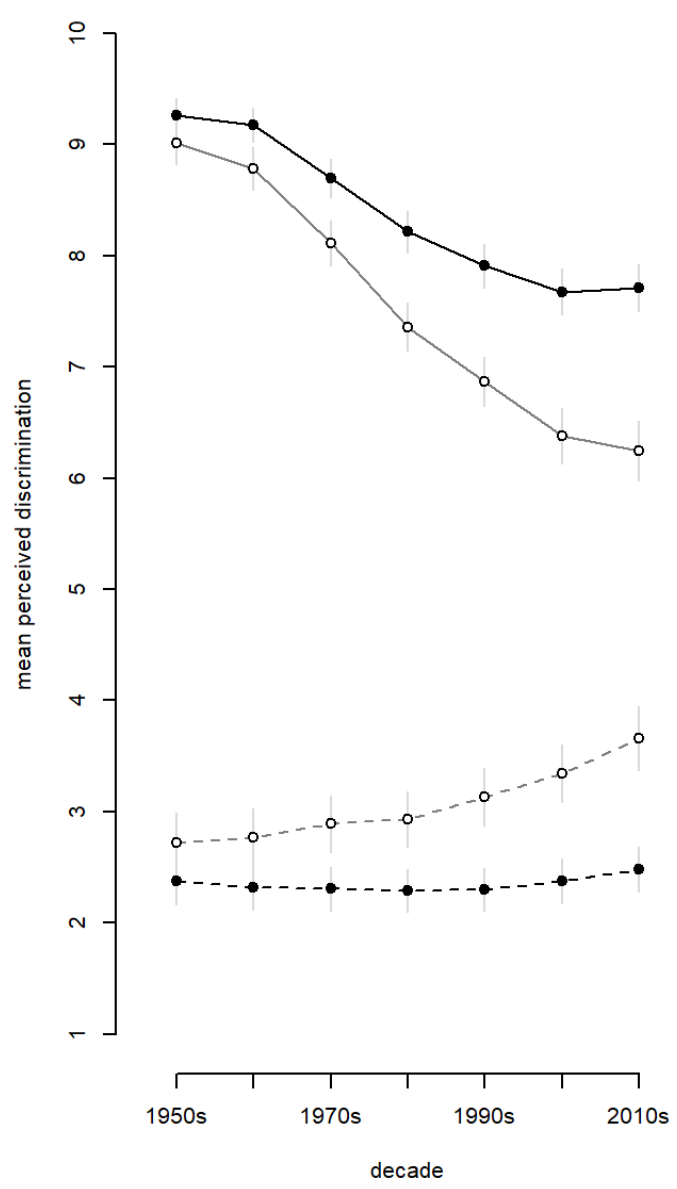

moderate

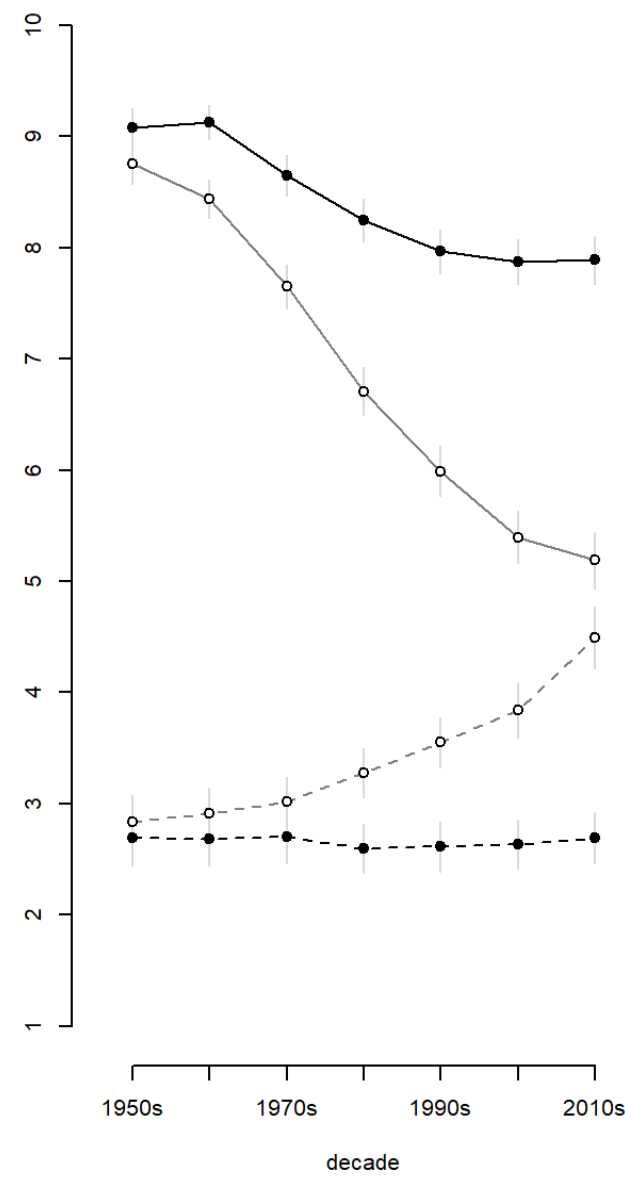

conservative

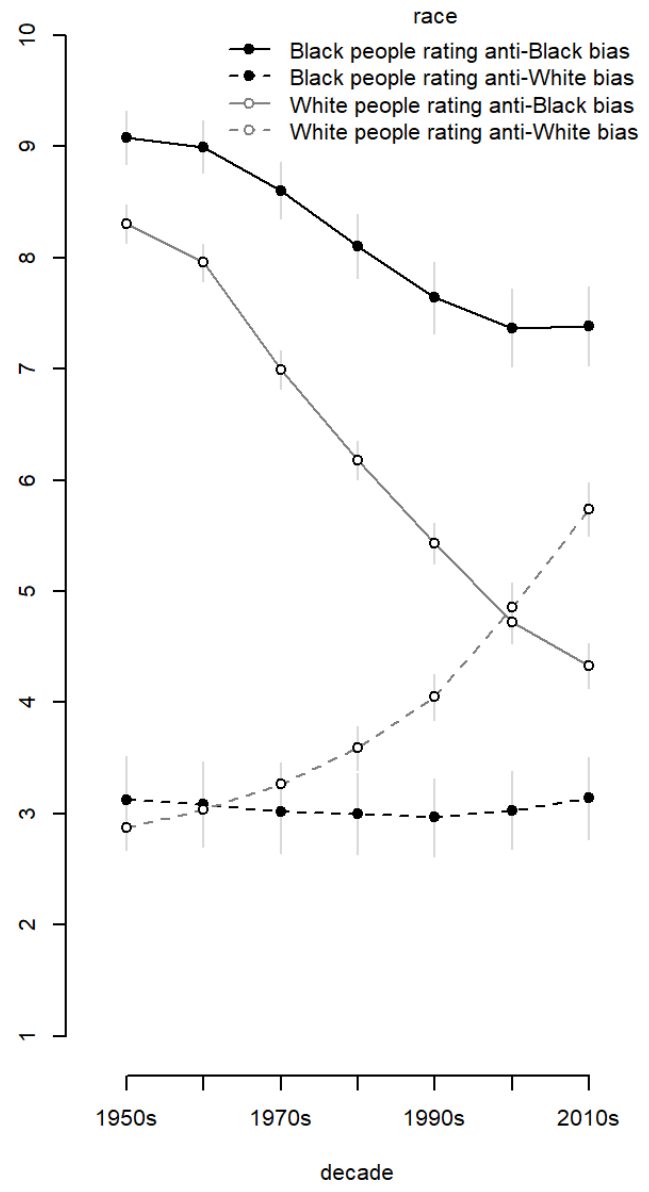

Figure 2. Discrimination against Black targets (solid lines) and White targets (dashed lines) perceived by Black participants (black lines with filled black circles) and White participants (gray lines with empty gray circles) by decade in October 2019. Panels depict results for liberals (left), moderates (middle), and conservatives (right). Error bars reflect 95\% confidence intervals. 


\section{Do White (but Not Black) Liberal, Moderate, and Conservative Americans Perceive}

\section{Racism as a Zero-Sum Game? Yes. For White Conservatives, It's a Game They Are Now}

\section{Losing}

As shown in Figure 2, White participants - liberals, moderates, and conservatives alike believed in 2019 that gains for Black people necessarily come at the expense of losses for White people. Specifically, regardless of political ideology, White participants believed that decreases in anti-Black bias were mirrored by increases in anti-White bias. However, only White conservatives $(n=714)$ believed that anti-White bias exceeded anti-Black bias in the 2010s, Hedges' $g=-0.47,95 \%$ CI[-0.58, -0.36$]$. White liberals $(n=462)$ believed that anti-Black bias exceeded anti-White bias by a lot in the 2010s, Hedges' $g=0.86,95 \% \mathrm{CI}[0.71,1.01]$; White moderates $(n=497)$ did too but only by a little, Hedges' $g=0.23,95 \%$ CI $[0.10,0.36] .{ }^{9}$

Black participants - liberals, moderates, and conservatives - did not demonstrate zerosum thinking; all three groups believed that decreases in anti-Black bias were paired with steady low levels of anti-White bias. Moreover, regardless of political ideology, Black participants

\footnotetext{
${ }^{9}$ The pattern in Figure 2 was supported by a statistically significant interaction between political ideology, participant race, target race, and decade. See Supplementary Table S4 for results of the confirmatory analysis of variance. In follow-up ANOVAs within each racial group, there were statistically significant interactions between political ideology, target race, and decade for White participants, $F(3.75,3,128.46)=33.16, M S E=7.82, p<.001$, $\eta^{2}{ }_{G}=.006$, and for Black participants, $F(5.48,4,140.44)=2.53, M S E=3.26, p=.023, \eta^{2}{ }_{G}<.001$.

In a follow-up exploratory analysis, we added gender as a fourth covariate. The four-way interaction between participant race, political ideology, target race, and decade remained statistically significant. In a second follow-up exploratory analysis, we added gender as a fifth factor instead of covariate and found a statistically significant, though marginal, five-way interaction, $F(12,18720)=1.81, p=.041$. Focusing on perceptions of White participants in the key decade, the 2010s, White liberal women, Hedges' $g=1.05,95 \% \mathrm{CI}[0.72,1.38]$, and men, Hedges' $g=.80$, $95 \% \mathrm{CI}[0.62,0.97]$, believed that anti-Black bias exceeded anti-White bias by a lot; the effect was bigger in women than men. White moderate women, Hedges' $g=0.41,95 \% \mathrm{CI}[0.16,0.67]$, and men, Hedges' $g=0.16,95 \% \mathrm{CI}[0.01$, $0.31]$, believed that anti-White bias exceeded anti-Black bias by a little; the effect was bigger in women than men. White conservative women, Hedges' $g=-0.24,95 \% \mathrm{CI}[-0.47,-0.002]$, and men, Hedges' $g=-0.55,95 \% \mathrm{CI}[-0.67$, 0.43], on the other hand, believed that anti-White bias exceeded anti-Black bias by a little; the effect was bigger in men than women. Overall, the conclusion that only White conservatives believed anti-White bias exceeded antiBlack bias in the 2010s was true for both men and women.
} 
believed that anti-Black bias exceeded anti-White bias in all decades, including the 2010s. In the 2010s, that effect was very large for Black liberals $(n=660)$, Hedges' $g=1.92,95 \% \mathrm{CI}[1.74$, 2.11], and Black moderates $(n=572)$, Hedges' $g=1.94,95 \% \mathrm{CI}[1.73,2.14]$, and smaller but still very large for Black conservatives $(n=286)$, Hedges' $g=1.36,95 \% \mathrm{CI}[1.14,1.58]$.

As shown in Figure 3, ratings of perceived bias against Black and White Americans were negatively associated for White participants in at least a few decades for all three ideology groups. ${ }^{10}$ Negative associations were most consistent among White conservatives and strongest in the most recent decades. But even White liberals exhibited negative associations in the three most recent decades. For Black participants, the associations between anti-Black bias and antiWhite bias hovered near zero in nearly all decades regardless of political ideology.

Finally, the association between perceived change in anti-Black bias from 1950 to 2010 (2010s minus 1950s) and perceived change in anti-White bias over the same time frame was not significantly moderated by participant race and political ideology group. ${ }^{11}$ For White liberals, $b=-0.14,95 \% \mathrm{CI}[-0.22,-0.06]$, White moderates, $b=-0.18,95 \% \mathrm{CI}[-0.26,-0.10]$, and White conservatives, $b=-0.25,95 \% \mathrm{CI}[-0.31,-0.18]$, larger perceived decreases in anti-Black bias were associated with larger perceived increases in anti-White bias. For Black liberals, $b=0.04$,

\footnotetext{
${ }^{10}$ We conducted another linear mixed-effects regression model using the lme4 package (Bates, et al., 2015) in R to determine whether political ideology group, participant race, and decade all moderated associations between antiBlack and anti-White bias. The criterion variable was anti-White bias with a random intercept for participants. Predictors were (centered) anti-Black bias, political ideology group, participant race, and decade. We also modeled age, education, and target race counterbalance order as covariates whose effects could vary by decade. The analysis revealed that the association between perceived anti-Black bias and anti-White bias depended on political ideology group, participant race, and decade, as captured by the four-way interaction term using the car package's Anova function with Type III sum of squares, $F(12,19158.1)=2.70, p=.001$. $P$ values are based on a Kenward-Roger F test with Satterthwaite degrees of freedom.

${ }^{11}$ We ran an ordinary least squares linear regression in which the criterion variable was change in ratings of antiWhite bias (2010s - 1950s). Predictors were change in ratings of anti-Black bias, participant race, and political ideology group. We also modeled age, education, and target race counterbalance order as covariates. The interaction between change in anti-Black bias, participant race, and political ideology group was not statistically significant using the car package's Anova function with Type III sum of squares, $F(2,3176)=0.06, p=.939$.
} 
$95 \%$ CI $[-0.04,0.12]$, Black moderates, $b=0.03,95 \% \mathrm{CI}[-0.05,0.12]$, and Black

conservatives, $b=-0.04,95 \% \mathrm{CI}[-0.14,0.06]$, the association between change in anti-Black bias and change in anti-White bias was near zero.

Collectively, these results demonstrate that, in 2019, liberal, moderate, and conservative White people continued to view racism as a zero-sum game. White liberals saw it as a game they were still winning by a lot, White moderates saw it as a game they were still winning by a little, and White conservatives saw this as a zero-sum game they were now losing by a little. 


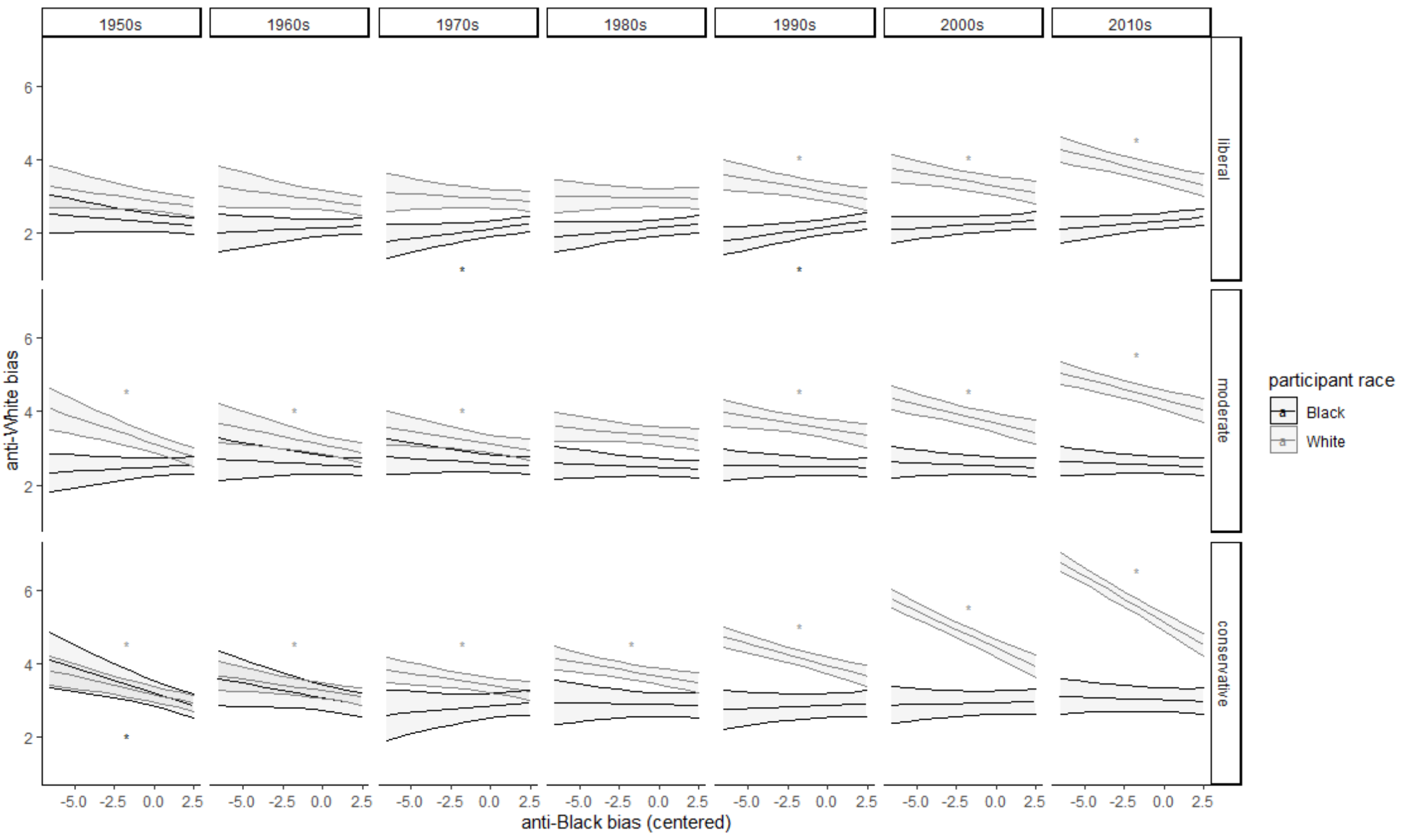

Figure 3. Associations between anti-Black bias (x axis) and anti-White bias (y axis) by participant race (straight black lines for Black participants, straight gray lines for White participants) in October 2019. Panels depict results for seven decades from the 1950s (left) to the 2010s (right) and three political ideology groups, liberals (top row), moderates (middle row), and conservatives (bottom row). Curved lines surrounding each association are 95\% confidence bands. Asterisks (black for Black participants, gray for White participants) indicate that the $95 \%$ confidence interval for the association excludes zero. 


\section{Conclusions}

Our results suggest that zero-sum thinking about racism pervades the entire political ideological spectrum among White Americans; even liberal White Americans believe that gains for Black people mean losses for White people. However, views of whether and by how much White people are seen as now winning or losing the zero-sum game vary by political ideology. Liberal, moderate, and conservative White Americans agree that White people were winning the zero-sum racism game in the past. They disagree on the outcome more recently; in the most recent decade, liberal White Americans see it as a game they are still winning by a lot, moderate White Americans see it as a game they are still winning but by a little, and conservative White Americans see racism as a zero-sum game they are now losing by a little.

Win or lose, why do White Americans, even liberal White Americans, view racism as a zero-sum game? The zero-sum pattern may be a logical consequence of structural racism, "racial practices that reproduce racial inequality in contemporary America [that] (1) are increasingly covert, (2) are embedded in normal operations of institutions, (3) avoid direct racial terminology, and (4) are invisible to most Whites" (Bonilla-Silva, 1997, p. 476). Racial progress by Black Americans may signal deviation from normal operations of American institutions, which is perceived as a threat to White Americans that motivates them to reassert cultural dominance (Wilkins et al., 2021).

That the zero-sum pattern was most pronounced among conservative White participants is not surprising. Work by Wilkins and Kaiser (2015) suggests that White people are more apt to perceive anti-White bias when they believe both that 1) there has been a lot of racial progress and that 2) the system is fair and that everyone can get ahead with hard work. Compared to Democrats, Republicans - who typically endorse conservative ideology - generally believe that 
America has made more racial progress (Horowitz et al., 2019). Furthermore, conservatism is correlated with economic system justification, the meritocratic belief that economic outcomes reflect individual efforts, not systemic advantage (Jost et al., 2017), and symbolic racism, a blend of antipathy toward Black people and the sense that Black people violate cherished American values (Henry \& Sears, 2002).

One striking similarity between the past work by Norton and Sommers (2011) and the current work is that White participants perceived racial inequity to be lowest (or reversed) in whatever was the most recent decade (i.e., in the 2000s for Norton \& Sommers, 2011, and in the 2010s for the current work). This pattern was most pronounced among those identifying as politically conservative. Thus, White participants - especially conservative White participants perceive racial inequity to be more a relic of history than a problem in present-day society. This view of racial inequity as a problem that has been solved - a perception often magnified by political viewpoint - may help explain slow progress towards racial equity despite evidence of persisting inequity (e.g., racial economic inequality; Kraus et al., 2019).

Consider, for example, the 2013 decision by the conservative-majority United States Supreme Court regarding preclearance provisions of the Voting Rights Act. ${ }^{12}$ Although Chief Justice Roberts (nominated by a Republican president) acknowledged that the Voting Rights Act "has proved immensely successful at redressing racial discrimination and integrating the voting process" (Shelby County v. Holder, 2013, p. 548), he also wrote, “Our country has changed,"

\footnotetext{
${ }^{12}$ On the strength of a 5-4 vote, the Court struck down provisions of the Voting Rights Act of 1965 in Section 4(b) outlining which jurisdictions needed to obtain approval - "preclearance" - from federal authorities to change voting procedures. The provisions were originally enacted to prevent racial discrimination by some state and local governments that had discriminatory prerequisites to voting and low voter registration and turnout.
} 
suggesting that some of the specific protections required by the Voting Rights Act were no longer necessary (Shelby County v. Holder, 2013, p. 557).

By contrast, in the dissenting opinion, Justice Ginsburg (nominated by a Democratic president) wrote, "Throwing out preclearance when it has worked and is continuing to work to stop discriminatory changes is like throwing away your umbrella in a rainstorm because you are not getting wet" (Shelby County v. Holder, 2013, p. 590). In the years since this ruling, numerous states in the United States have passed measures that restrict access to voting (American Civil Liberties Union, 2021). Better understanding differing perceptions of discrimination as a function of political ideology, thus, has clear practical importance.

One striking difference between the past work by Norton and Sommers (2011) and the current work is that our present White participants overall did not perceive racism to be a zerosum game they are now losing; only those endorsing conservative ideology perceived racism as such. Why? We summarize several potential explanations in Table 3. Some explanations hinge on the idea that a critical variable may have changed between 2011 and 2018/2019. For example, with a multiracial president in office in 2011, White Americans' perceptions of discrimination may have reflected concern that they were being supplanted in positions of power, a concern that was less salient with a White Republican president in office in 2018/2019. In addition (or instead), perceptions of anti-Black bias may have changed over time, perhaps due to proliferation of video evidence of racism (e.g., cellphone or bodycam footage of police brutality) and heightened visibility of movements such as Black Lives Matter via social media (Auxier, 2020). Other explanations hinge on methodological differences between the studies.

Common to almost all potential explanations is a need for future research because our data do not afford definitive conclusions. Thus, we hope the present work inspires future 
research that explains why only conservative White Americans believe White people are losing the zero-sum game when it comes to racism. Longitudinal studies could reveal to what extent zero-sum thinking precedes and/or reflects political and racial events and attitudes over time. Experimental studies could reveal whether manipulations of political and racial attitudes (e.g., asking conservative participants to reflect on their political values) are sufficient to cause shifts in zero-sum thinking.

Future work should also consider individual-difference variables of interest. For example, clever work by Wilkins and colleagues (2015) suggests it would be fruitful to measure global zero-sum beliefs that gains for one group represent losses for another. They found, for example, that men who endorse higher levels of zero-sum beliefs are more likely than men who endorse lower levels of zero-sum beliefs to think that declines in anti-female bias over the decades are in lockstep with increases in anti-male bias, and that men are losing this zero-sum gender bias game in the most recent decade. Global zero-sum beliefs may partially or fully explain conservative White Americans' view that racism is a game they are now losing. 
Table 3. Possible reasons for perception by White Americans that they were losing the zero-sum game when studied by Norton and

Sommers (2011) but not when studied by us in 2018/2019.

\section{Reason}

Change in political landscape

Increase in perceptions of anti-Black bias over time

Decrease in symbolic racism over time

Increase in liberal values over time

Difference in sampling
How this could explain divergent results

Multiracial (Black/White) Democrat Barack Obama was president in 2011. White Republican Donald Trump was president in 2018/2019. Perceptions of discrimination by White Americans in 2011 may have reflected concern that White Americans were being supplanted in positions of power, a concern that was less salient with a White Republican president in 2018/2019.

Proliferation of video evidence of racism and heightened visibility of movements such as Black Lives Matter via social media may have prompted greater recognition of anti-Black bias among White Americans. Consistent with this idea, White Americans' perceptions of anti-White bias in the most recent decade were similar in Norton and Sommers (2011) and in the present data collected in 2019. By contrast, White Americans' perceptions of anti-Black bias in the most recent decade were about $1 \frac{1}{2}$ points higher in 2019 compared to 2011. If these cross-sectional differences reflect change over time, then it appears White people recognized anti-Black bias more in the recent sample.

Per Henry and Sears (2002), lower symbolic racism in 2018/2019 would mean less belief that Black people no longer face much prejudice and less of the sense that Black people have gotten more than they deserve.

An increase in liberal identification over time (c.f., Saad, 2021) would mean conservative participants were represented proportionally more in Norton and Sommers (2011) than in our samples in $2018 / 2019$.

Different sampling techniques may have resulted in different sample characteristics. Consistent with this idea, the White participants in the 2019 sample were the same mean age but slightly less educated and proportionally fewer were women compared to 2011. Political ideology was not assessed in 2011 but it is possible that conservative participants were represented proportionally more in Norton and Sommers (2011) than in our samples in 2018/2019. 
Change from fixed to

counterbalanced rating order
Norton and Sommers (2011) had participants rate perceived discrimination against Black Americans first. This may have magnified the perception of backlash among White participants. Counterbalancing in 2018/2019 was intended to prevent systematic bias due to order and may have reduced perception of backlash among White participants. Inconsistent with this, however, plots showing perceived discrimination separately for people who rated Black American targets first versus second do not reveal greater anti-White than anti-Black bias in the most recent decade for either order. See Figure S3. 
Norton and Sommers (2011) concluded by stating, "In sum, our findings situate specific claims of persecution by White Americans in a broader belief in a new, generalized anti-White bias. That Whites now believe that anti-White bias is more prevalent than anti-Black bias has clear implications for public policy debates and behavioral science research in the years to come." Our current results qualify this specific claim to be more narrowly restricted to White Americans who identify as conservative. Importantly, liberal, moderate, and conservative White Americans alike believe that racism is a zero-sum game with gains for Black people meaning losses for White people. Liberal White Americans see racism as a zero-sum game they are winning by a lot, moderate White Americans see it as a game they are winning by only a little, and conservative White Americans see it as a game they are losing. Liberal, moderate, and conservative Black Americans continue not to see racism as a zero-sum game at all. Thus, perceptions of discrimination based on intersecting racial and political identities remain important considerations for public policy and social science into future decades. 


\section{References}

Abramowitz, A., \& McCoy, J. (2019). United States: Racial Resentment, Negative Partisanship, and Polarization in Trump's America. The ANNALS of the American Academy of Political and Social Science, 681(1), 137-156. https://doi.org/10.1177/0002716218811309

American Civil Liberties Union. (2021). The Battle to Protect the Ballot: Voter Suppression Measures Passed Since 2013. https:/www.aclu.org/issues/voting-rights/fighting-votersuppression/battle-protect-ballot-voter-suppression-measures

APM Research Lab. (2020). COVID-19 deaths analyzed by race and ethnicity. https://www.apmresearchlab.org/covid/deaths-by-race

Aust, F. \& Barth, M. (2020). papaja: Prepare reproducible APA journal articles with $R$ Markdown. (Version 0.1.0.9997) [Computer software]. https://github.com/crsh/papaja Bates, D., Maechler, M., Bolker, B., Walker, S. (2015). Fitting Linear Mixed-Effects Models Using lme4. Journal of Statistical Software, 67(1), 1-48. doi:10.18637/jss.v067.i01

Blackall, M. (2020). First Thing: Trump denies police racism is "systemic" on Kenosha visit. The Guardian. https://www.theguardian.com/us-news/2020/sep/02/first-thing-trump-deniespolice-racism-is-systemic-on-kenosha-visit

Bonilla-Silva, E. (1997). Rethinking Racism: Toward a Structural Interpretation. American Sociological Review, 62(3), 465-480. https://doi.org/10.2307/2657316

Cowie, J. (2016). History Behind the "Forgotten Man" in Trump's Victory Speech. Time Magazine. https://ime.com/4567949/forgotten-man-donald-trump/

Craig, M. A., \& Richeson, J. A. (2017). Information about the US racial demographic shift triggers concerns about anti-White discrimination among the prospective White "minority." PLOS ONE, 12(9), e0185389. https://doi.org/10.1371/journal.pone.0185389 
Dover, T. L., Major, B., \& Kaiser, C. R. (2016). Members of high-status groups are threatened by pro-diversity organizational messages. Journal of Experimental Social Psychology, 62, 58-67. https://doi.org/10.1016/j.jesp.2015.10.006

EdBuild. (2019). \$23 BILLION. https://edbuild.org/content/23-billion/full-report.pdf

Edwards, F., Lee, H., \& Esposito, M. (2019). Risk of being killed by police use of force in the United States by age, race-ethnicity, and sex. Proceedings of the National Academy of Sciences of the United States of America, 116(34), 16793-16798.

https://doi.org/10.1073/pnas.1821204116

Grieco, E. (2020). Americans' main sources for political news vary by party and age. Pew Research Center. https://www.pewresearch.org/fact-tank/2020/04/01/americans-mainsources-for-political-news-vary-by-party-and-age/

Henry, P. J., \& Sears, D. O. (2002). The Symbolic Racism 2000 Scale. Political Psychology, 23(2), 253-283. https://doi.org/10.1111/0162-895X.00281

Horowitz, J., Brown, A., \& Cox, K. (2019). Race in America 2019. Pew Research Center. https://www.pewsocialtrends.org/2019/04/09/race-in-america2019/?fbclid=IwAR3QIsTuS4hY2Z4YQDM9sUusQyb3QfH4Ogvn91dmxxAPpwPZbPbd0Edzvo

Jost, J. T., Glaser, J., Kruglanski, A. W., \& Sulloway, F. J. (2003). Political Conservatism as Motivated Social Cognition. Psychological Bulletin, 129(3), 339-375. https://doi.org/10.1037/0033-2909.129.3.339

Jost, J. T., Langer, M., Badaan, V., Azevedo, F., Etchezahar, E., Ungaretti, J., \& Hennes, E. P. (2017). Ideology and the limits of self-interest: System justification motivation and 
conservative advantages in mass politics. Translational Issues in Psychological Science, 3(3), e1-e26. http://dx.doi.org/10.1037/tps0000127

King, M. (2015). The 'knockout game': moral panic and the politics of white victimhood. Race \& Class, 56(4), 85-94. https://doi.org/10.1177/0306396814567411

Kraus, M., Hudson, S. T. J., \& Richeson, J. (2020). Framing, Context, and the Misperception of Black-White Wealth Inequality. https://doi.org/10.31234/osf.io/4vwnb

Kraus, M. W., Onyeador, I. N., Daumeyer, N. M., Rucker, J. M., \& Richeson, J. A. (2019). The misperception of racial economic inequality. Perspectives on Psychological Science, 14(6), 899-921. https://doi.org/10.1177/1745691619863049

Levay, K. E., Freese, J., \& Druckman, J. N. (2016). The Demographic and Political Composition of Mechanical Turk Samples. SAGE Open. https://doi.org/10.1177/2158244016636433

McIntosh, K., Moss, E., Nunn, R., \& Shambaugh, J. (2020). Examining the Black-white wealth gap. Brookings. https://www.brookings.edu/blog/up-front/2020/02/27/examining-the-blackwhite-wealth-gap

Norton, M. I., \& Sommers, S. R. (2011). Whites see racism as a zero-sum game that they are now losing. Perspectives on Psychological Science, 6(3), 215-218. https://doi.org/10.1177/1745691611406922

Pew Research Center (2019). Sharp Rise in the Share of Americans Saying Jews Face Discrimination. https://www.pewresearch.org/politics/2019/04/15/sharp-rise-in-the-shareof-americans-saying-jews-face-discrimination/

Saad, L. (2021). Americans' Political Ideology Held Steady in 2020. https://news.gallup.com/poll/328367/americans-political-ideology-held-steady-2020.aspx 
Shelby County, Alabama v. Holder, Attorney General, et al. 570 U. S. 529 (2013). https://www.supremecourt.gov/opinions/boundvolumes/570bv.pdf

Singmann, H., Bolker, B., Westfall, J., Aust, F., \& Ben-Shachar, M. S. (2020). afex: Analysis of Factorial Experiments. (Version 0.28-0) [Computer software]. https://CRAN.Rproject.org/package $=$ afex

Tesler, M. (2016). Views about race mattered more in electing Trump than in electing Obama. Washington Post. https://www.washingtonpost.com/news/monkeycage/wp/2016/11/22/peoples-views-about-race-mattered-more-in-electing-trump-than-inelecting-obama/

Torchiano, M. (2020). effsize: Efficient Effect Size Computation. (Version 0.8.0) [Computer software]. https://doi.org/10.5281/zenodo.1480624

Wilkins, C. L., Wellman, J. D., Babbitt, L. G., Toosi, N. R., \& Schad, K. D. (2015). You can win but I can't lose: Bias against high-status groups increases their zero-sum beliefs about discrimination. Journal of Experimental Social Psychology, 57, 1-14. https://doi.org/10.1016/j.jesp.2014.10.008

Wilkins, C. L., Wellman, J., Toosi, N. R., Miller, C., Lisnek, J. A., \& Martin, L. A. (2021). Is LGBT progress seen as an attack on Christians?: Examining Christian/sexual orientation zero-sum beliefs. PsyArXiv. https://doi.org/10.31234/osf.io/hc46b 


\section{Supplemental Materials}

\section{Initial Small-scale Study in April 2018}

In April 2018, we recruited 300 adults in the U.S. via Amazon Mechanical Turk. The purpose of this initial study was to replicate in part the original study by Norton and Sommers (2011). We also explored whether political ideology moderates White people's perceptions of racism as a zero-sum game. Materials, data, and code are available at https://osf.io/uver2.

We used a 2 [Target race: Black, White] $\times 7$ [Decade: 1950s, 1960s, 1970s, 1980s, 1990s, 2000s, 2010s] within-subjects factorial design to evaluate perceptions of anti-Black and anti-White bias. Participants indicated to what extent they thought Black and White Americans, in counterbalanced order, were the target of discrimination $(1=$ not at all to $10=$ very $m u c h)$ in each of the past seven decades. After completing these perceived bias measures, participants reported their political ideology ${ }^{13}$, race/ethnicity, education, and age.

We present sample characteristics (age, gender, and political ideology by race/ethnicity) in Supplementary Table S1, and graph results for White participants $(n=235)$ in Supplementary Figure S1. ${ }^{14}$ See Supplementary Table S2 for results of the confirmatory analysis of variance. ${ }^{15}$

\footnotetext{
${ }^{13}$ Participants indicated their political ideology on a scale from 1 (extremely liberal) to 7 (extremely conservative). Participants who responded 1 (extremely liberal), 2 (liberal), or 3 (slightly liberal) were coded as "liberal." Participants who responded 4 (moderate/middle of the road) were coded as "moderate." Participants who responded 5 (slightly conservative), 6 (conservative), or 7 (extremely conservative) were coded as "conservative."

${ }^{14}$ We preregistered this focus on White participants. We had funding to permit collecting data from $N=300$. Assuming Mechanical Turk has about 7\% Black and 72\% White members (Levay, Freese, \& Druckman, 2016), we expected this sample size would be more than sufficient to detect the key correlation between change over time in perceived anti-White and anti-Black bias from the 1950s to the 2000s among White participants. Norton \& Sommers (2011) found an effect size of $r=-.28,60 \%$ CI [-.33, -.22]. We would only have needed at least $N=159$ to have $80 \%$ power to detect $r=-.22$ (upper $60 \% \mathrm{CI}$ ) with a two-tailed alpha of .05 . We recruited more than that to support detection of effects in other studies that were bundled with this one.

${ }^{15}$ We conducted an ANOVA with target race and decade as within-subjects factors, and age, education, and target race counterbalance order as between-subjects covariates. This revealed a statistically significant two-way interaction between target race and decade (see Table S2). Including target race counterbalance order in this model deviated from the preregistered analysis plan; the interaction between target race and decade is statistically significant with or without its inclusion.
} 
Table S1. Sample characteristics in the initial study in April 2018.

\begin{tabular}{|c|c|c|c|c|c|c|c|c|}
\hline & $\begin{array}{c}\text { Total } \\
N=300\end{array}$ & $\begin{array}{c}\text { Asian/Pacifi } \\
\text { c Islander } \\
n=18\end{array}$ & $\begin{array}{c}\text { Black } \\
n=17\end{array}$ & $\begin{array}{c}\text { Hispanic or } \\
\text { Latino/a/x } \\
n=14\end{array}$ & $\begin{array}{c}\text { Multiracia } \\
1 \\
n=6\end{array}$ & $\begin{array}{c}\text { Native } \\
\text { American } \\
n=1\end{array}$ & $\begin{array}{c}\text { White } \\
n=235\end{array}$ & $\begin{array}{l}\text { Declined to } \\
\text { provide } \\
\text { race/ethnicity } \\
n=9\end{array}$ \\
\hline \multicolumn{9}{|l|}{ Age in years } \\
\hline$M(S D)$ & $35.4( \pm 10.8)$ & $31.1( \pm 8.9)$ & $31.8( \pm 7.9)$ & $32.4( \pm 4.7)$ & $\begin{array}{c}26.3 \\
( \pm 2.3)\end{array}$ & $44.0( \pm)$ & $36.4( \pm 11.3)$ & $35.0( \pm 12.1)$ \\
\hline Declined & $5(1.7 \%)$ & $0(0 \%)$ & $0(0 \%)$ & $0(0 \%)$ & $0(0 \%)$ & $0(0 \%)$ & $0(0 \%)$ & $5(55.6 \%)$ \\
\hline \multicolumn{9}{|l|}{ Gender } \\
\hline Man & $173(57.7 \%)$ & $9(50.0 \%)$ & $7(41.2 \%)$ & $9(64.3 \%)$ & $5(83.3 \%)$ & $1(100.0 \%)$ & $139(59.1 \%)$ & $3(33.3 \%)$ \\
\hline Nonbinary & $2(0.7 \%)$ & $0(0.0 \%)$ & $0(0.0 \%)$ & $0(0.0 \%)$ & $1(16.7 \%)$ & $0(0.0 \%)$ & $1(0.4 \%)$ & $0(0.0 \%)$ \\
\hline Woman & $119(39.7 \%)$ & $9(50.0 \%)$ & $10(58.8 \%)$ & $5(35.7 \%)$ & $0(0.0 \%)$ & $0(0.0 \%)$ & $94(40.0 \%)$ & $1(11.1 \%)$ \\
\hline Declined & $6(2.0 \%)$ & $0(0.0 \%)$ & $0(0.0 \%)$ & $0(0.0 \%)$ & $0(0.0 \%)$ & $0(0.0 \%)$ & $1(0.4 \%)$ & $5(55.6 \%)$ \\
\hline \multicolumn{9}{|l|}{ Political Ideology } \\
\hline Conservative & $80(26.7 \%)$ & $1(5.6 \%)$ & $3(17.6 \%)$ & $4(28.6 \%)$ & $0(0.0 \%)$ & $0(0.0 \%)$ & $69(29.4 \%)$ & $3(33.3 \%)$ \\
\hline Moderate & $57(19.0 \%)$ & $3(16.7 \%)$ & $3(17.6 \%)$ & $1(7.1 \%)$ & $2(33.3 \%)$ & $0(0.0 \%)$ & $47(20.0 \%)$ & $1(11.1 \%)$ \\
\hline Liberal & $158(52.7 \%)$ & $14(77.8 \%)$ & $10(58.8 \%)$ & $9(64.3 \%)$ & $4(66.7 \%)$ & $1(100.0 \%)$ & $117(49.8 \%)$ & $3(33.3 \%)$ \\
\hline Declined & $5(1.7 \%)$ & $0(0.0 \%)$ & $1(5.9 \%)$ & $0(0.0 \%)$ & $0(0.0 \%)$ & $0(0.0 \%)$ & $2(0.9 \%)$ & $2(22.2 \%)$ \\
\hline
\end{tabular}

Note. Analyses focused on the White participants, shaded in light gray. 


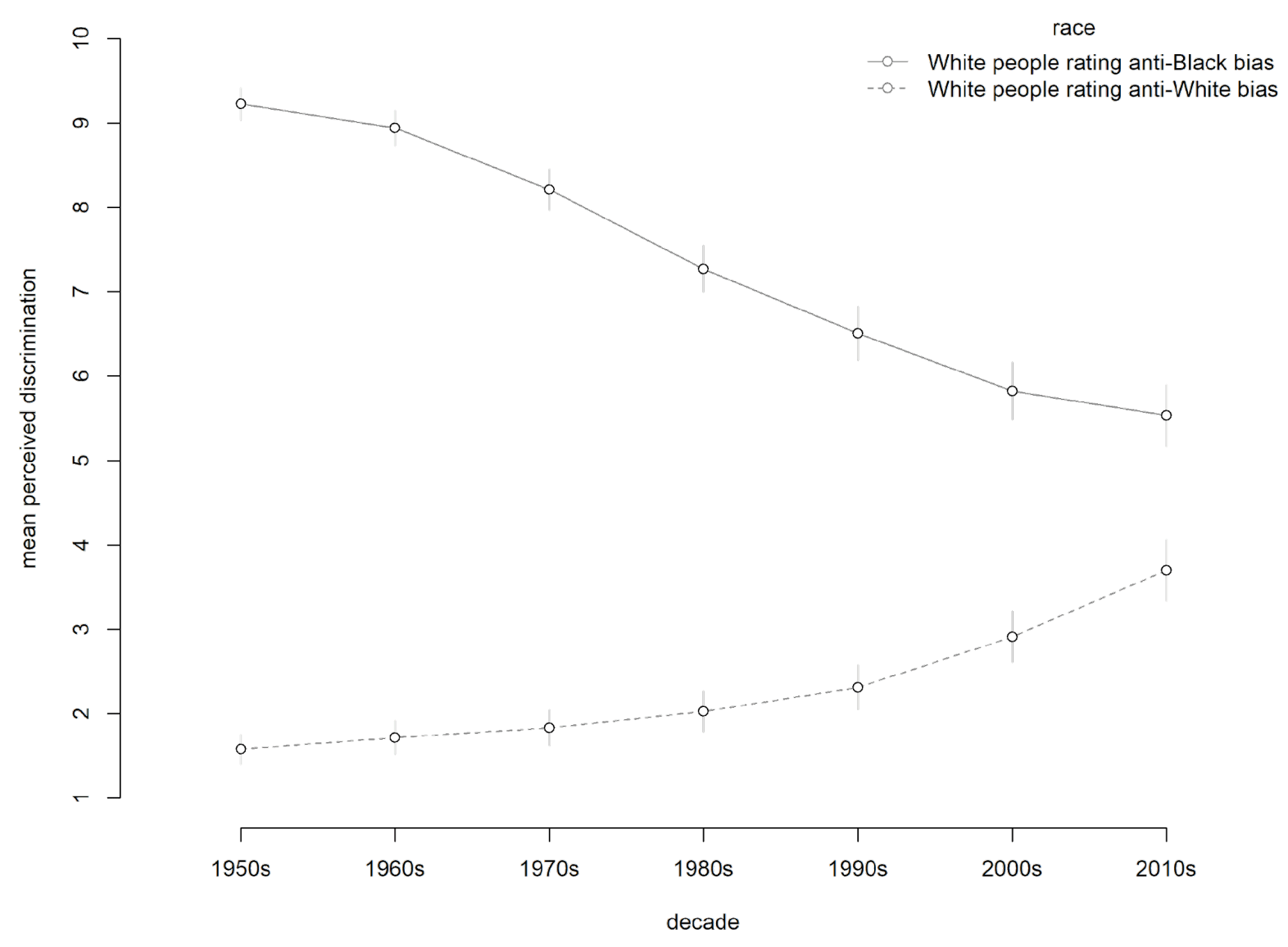

Figure S1. Discrimination against Black targets (solid line) and White targets (dashed line) perceived by White participants (gray lines with empty gray circles) by decade in April 2018. Error bars reflect $95 \%$ confidence intervals.

Consistent with Norton and Sommers (2011), White participants demonstrated zero-sum thinking. They believed that anti-Black bias decreased from the 1950s to the 2010s whereas antiWhite bias increased from the 1950 s to the 2010 s. In terms of effect size, our White participants endorsed a very large perceived difference between anti-Black and anti-White bias in the 1950s, Hedges' $g=5.35,95 \%$ CI[4.54, 6.17], that shrank to a medium difference in the 2010s, Hedges' $g=0.64,95 \% \mathrm{CI}[0.42,0.87]$. 
Table S2. Results of confirmatory analysis of variance in perceived discrimination among White participants in April 2018

\begin{tabular}{|c|c|c|c|c|c|c|}
\hline Effect & $F$ & $d f_{1}^{G G}$ & $d f_{2}^{G G}$ & MSE & $p$ & $\eta^{2}{ }_{G}$ \\
\hline Age (centered) & 0.08 & 1 & 230 & 16.21 & 0.781 & 0 \\
\hline Education (centered) & 1.09 & 1 & 230 & 16.21 & 0.298 & 0.001 \\
\hline Target Race Counterbalance Order & 5.71 & 1 & 230 & 16.21 & 0.018 & 0.006 \\
\hline Target Race & 709.1 & 1 & 230 & 29.26 & $<.001$ & 0.593 \\
\hline Decade & 70.5 & 2.2 & 505.6 & 2.95 & $<.001$ & 0.031 \\
\hline Age $($ centered $) \times$ Target Race & 0.22 & 1 & 230 & 29.26 & 0.64 & 0 \\
\hline Education $($ centered) $\times$ Target Race & 0.38 & 1 & 230 & 29.26 & 0.54 & 0.001 \\
\hline Target Race Counterbalance Order $\times$ Target Race & 0.01 & 1 & 230 & 29.26 & 0.935 & 0 \\
\hline Age $($ centered $) \times$ Decade & 0.25 & 2.2 & 505.6 & 2.95 & 0.797 & 0 \\
\hline Education $($ centered $) \times$ Decade & 0.35 & 2.2 & 505.6 & 2.95 & 0.727 & 0 \\
\hline Target Race Counterbalance Order $\times$ Decade & 10.76 & 2.2 & 505.6 & 2.95 & $<.001$ & 0.005 \\
\hline Target Race $\times$ Decade & 336.85 & 1.76 & 404.71 & 5.6 & $<.001$ & 0.189 \\
\hline Age $($ centered $) \times$ Target Race $\times$ Decade & 3.26 & 1.76 & 404.71 & 5.6 & 0.046 & 0.002 \\
\hline Education $($ centered) $\times$ Target Race $\times$ Decade & 0.62 & 1.76 & 404.71 & 5.6 & 0.519 & 0 \\
\hline Target Race Counterbalance Order $\times$ Target Race $\times$ Decade & 0.33 & 1.76 & 404.71 & 5.6 & 0.692 & 0 \\
\hline
\end{tabular}

Note. Degrees of freedom are Greenhouse-Geisser (GG) corrected. $\eta^{2}{ }_{G}$ is generalized eta-squared, a measure of effect size. To bring results into alignment with the large-scale study in October 2019, we deviated from our preregistered analysis plan by including target race counterbalance order as a covariate in this analysis. The addition of this covariate does not alter conclusions. 
Also consistent with Norton and Sommers (2011), White participants' ratings of perceived bias against White and Black Americans were negatively correlated within each decade $(-0.36 \leq r \leq-0.20$, all $p \mathrm{~s} \leq 0.002$; mean $r=-0.26)$. In addition, larger perceived decreases in anti-Black bias from 1950 to 2010 (2010s minus 1950s) were associated with larger perceived increases in anti-White bias over the same time frame, $r=-.25,95 \% \mathrm{CI}[-.37,-.13], t(232)=$ $-4.00, p<.001$. However, inconsistent with Norton and Sommers (2011), anti-White bias did not exceed anti-Black bias in any decade in our White participants. Reasoning that people with liberal, moderate, and conservative political attitudes might perceive things differently, we added political ideology as a between-subjects factor in an exploratory analysis of variance. ${ }^{16}$ This analysis revealed a statistically significant three-way interaction between political ideology, target race, and decade (see results in Supplementary Table S3).

Whereas White liberals $(n=117)$ believed that anti-Black bias exceeded anti-White bias in the 2010s, Hedges' $g=1.90,95 \% \mathrm{CI}[1.41,2.39]$, White moderates $(n=47)$ believed that antiBlack bias was similar to anti-White bias in the 2010s, Hedges' $g=-0.02,95 \%$ CI[-0.42, 0.38]. Moreover, White conservatives $(n=69)$ believed that anti-White bias exceeded anti-Black bias in the 2010s, Hedges' $g=-0.44,95 \%$ CI[-0.78, -0.10] (see Supplementary Figure S2).

\footnotetext{
${ }^{16}$ Participants indicated their political ideology on a scale from 1 (extremely liberal) to 7 (extremely conservative). Participants who responded 1 (extremely liberal), 2 (liberal), or 3 (slightly liberal) were coded as "liberal." Participants who responded 4 (moderate/middle of the road) were coded as "moderate." Participants who responded 5 (slightly conservative), 6 (conservative), or 7 (extremely conservative) were coded as "conservative."

We conducted an exploratory ANOVA with target race and decade as within-subjects factors, political ideology group as a between-subjects factor, and age, education, and target race counterbalance order as between-subjects covariates.
} 
liberal

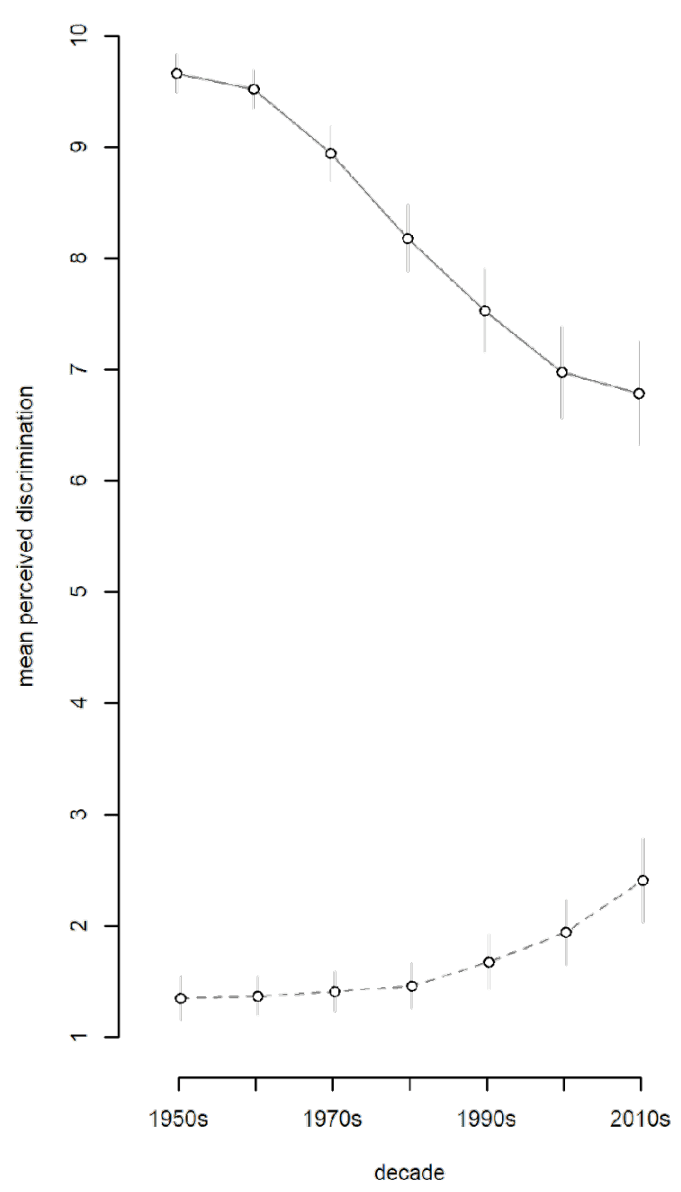

moderate

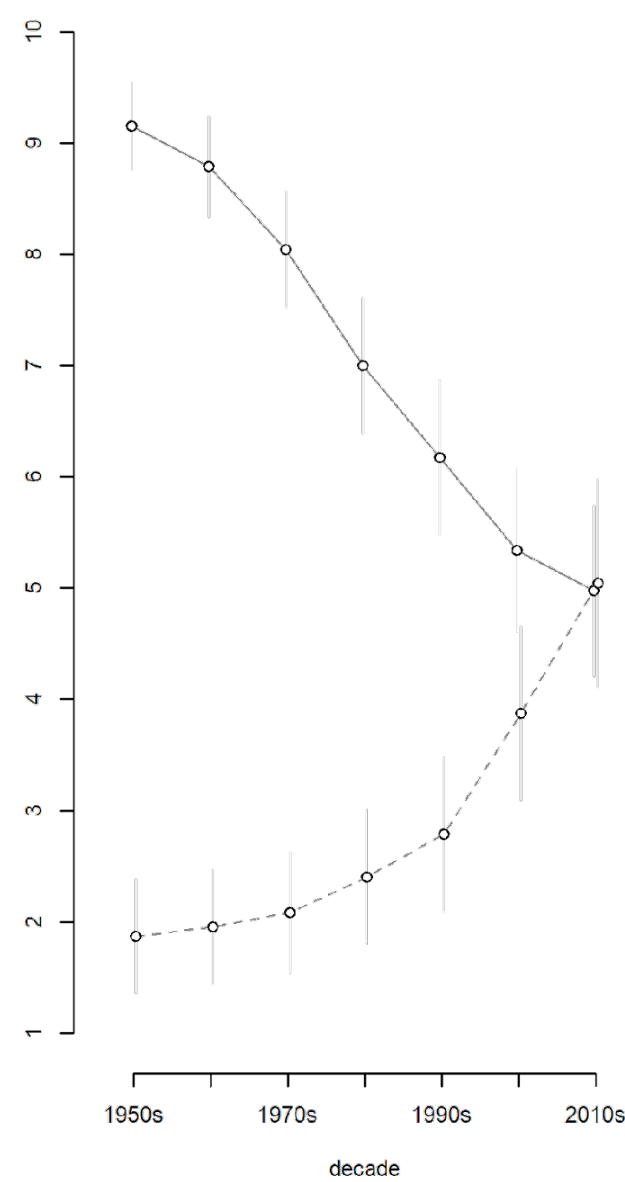

conservative
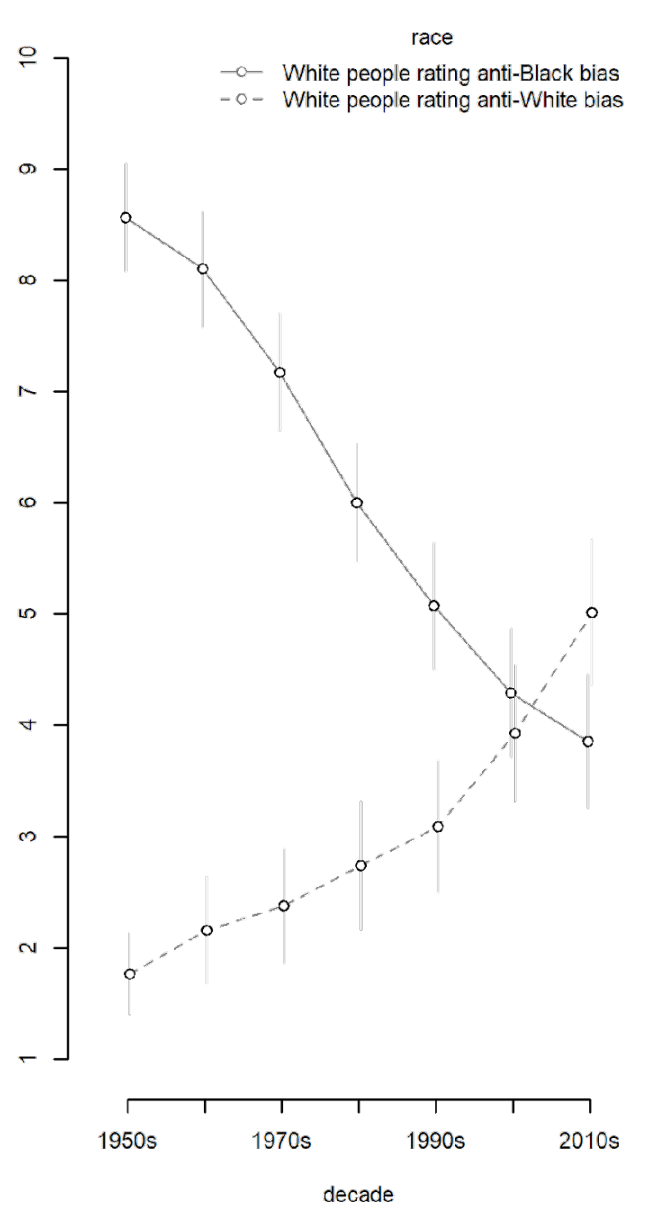

Figure S2. Discrimination against Black targets (solid lines) and White targets (dashed lines) perceived by White participants (gray lines with empty gray circles) by decade in April 2018. Panels depict results for liberals (left), moderates (center), and conservatives (right). Error bars reflect 95\% confidence intervals. 
Table S3. Results of exploratory analysis of variance in perceived discrimination in April 2018

\begin{tabular}{|c|c|c|c|c|c|c|}
\hline Effect & $F$ & $d f_{1}^{G G}$ & $d f_{2}^{G G}$ & $M S E$ & $p$ & $\eta^{2}{ }_{G}$ \\
\hline Political Ideology & 2.43 & 2 & 227 & 15.69 & 0.091 & 0.006 \\
\hline Age (centered) & 0.46 & 1 & 227 & 15.69 & 0.499 & 0.001 \\
\hline Education (centered) & 0.31 & 1 & 227 & 15.69 & 0.578 & 0 \\
\hline Target Race Counterbalance Order & 5.5 & 1 & 227 & 15.69 & 0.02 & 0.007 \\
\hline Target Race & 701.24 & 1 & 227 & 20.9 & $<.001$ & 0.556 \\
\hline Decade & 56.33 & 2.22 & 502.87 & 2.88 & $<.001$ & 0.03 \\
\hline Political Ideology $\times$ Target Race & 47.11 & 2 & 227 & 20.9 & $<.001$ & 0.144 \\
\hline Age $($ centered $) \times$ Target Race & 0.25 & 1 & 227 & 20.9 & 0.617 & 0 \\
\hline Education $($ centered) $\times$ Target Race & 0 & 1 & 227 & 20.9 & 0.948 & 0 \\
\hline Target Race Counterbalance Order $\times$ Target Race & 1.88 & 1 & 227 & 20.9 & 0.172 & 0.003 \\
\hline Political Ideology $\times$ Decade & 1.85 & 4.43 & 502.87 & 2.88 & 0.11 & 0.002 \\
\hline Age $($ centered $) \times$ Decade & 0.27 & 2.22 & 502.87 & 2.88 & 0.787 & 0 \\
\hline Education $($ centered $) \times$ Decade & 0.42 & 2.22 & 502.87 & 2.88 & 0.676 & 0 \\
\hline Target Race Counterbalance Order $\times$ Decade & 12.46 & 2.22 & 502.87 & 2.88 & $<.001$ & 0.007 \\
\hline Target Race $\times$ Decade & 403.76 & 1.91 & 433.02 & 4.5 & $<.001$ & 0.229 \\
\hline Political Ideology $\times$ Target Race $\times$ Decade & 18.05 & 3.82 & 433.02 & 4.5 & $<.001$ & 0.026 \\
\hline Age $($ centered $) \times$ Target Race $\times$ Decade & 2.1 & 1.91 & 433.02 & 4.5 & 0.127 & 0.002 \\
\hline Education $($ centered $) \times$ Target Race $\times$ Decade & 1.09 & 1.91 & 433.02 & 4.5 & 0.336 & 0.001 \\
\hline Target Race Counterbalance Order $\times$ Target Race $\times$ Decade & 0.4 & 1.91 & 433.02 & 4.5 & 0.659 & 0 \\
\hline
\end{tabular}

Note. Degrees of freedom are Greenhouse-Geisser (GG) corrected. $\eta^{2}{ }_{G}$ is generalized eta-squared, a measure of effect size. 


\section{Large-scale Study in October 2019}

Table S4 presents full results of confirmatory analysis of variance in the large-scale study fielded in October 2019.

In Table S5, we present estimates of linear change in perceived discrimination across decades by participant race and political ideology; negative numbers indicate that perceived discrimination decreased since the 1950 s whereas positive numbers indicate that it increased since the 1950s. These values confirm what is obvious on visual inspection of Figure 1 in the main manuscript. White Americans in all three political ideology groups, including White liberals, espoused zero-sum thinking; gains for Black people were perceived as coming at the expense of White people. Moreover, there were monotonic increases in the slope magnitude as a function of political ideology for White Americans. White liberals perceived the smallest decreases in anti-Black bias over the decades and the smallest increases in anti-White bias over the decades, but both slopes were statistically significant. White conservatives perceived the biggest decreases in anti-Black bias over the decades and the biggest increases in anti-White bias over the decades. White moderates fell in between.

Figure S3 shows results for participants who rated perceived discrimination against Black American targets first (left) or second (right). Results are very similar, suggesting that rating Black American targets first did not push for perception of backlash among White participants. If anything, rating Black American targets first increased perception of racial inequity. The fact that Norton and Sommers (2011) did not counterbalance whereas we did thus seems implausible as an explanation for why White participants overall did not perceive racism to be a zero-sum game they were losing in 2018/2019. 
Table S4. Results of confirmatory analysis of variance in perceived discrimination in October 2019

\begin{tabular}{|c|c|c|c|c|c|c|}
\hline Effect & $F$ & $d f_{1}^{G G}$ & $d f_{2}^{G G}$ & $M S E$ & $p$ & $\eta_{G}^{2}$ \\
\hline Participant Race & 1.09 & 1 & 369 & 37.38 & 0.296 & 0.001 \\
\hline Political Ideology & 1.05 & 2 & 369 & 37.38 & 0.35 & 0.002 \\
\hline Age (centered) & 1.69 & 1 & 369 & 37.38 & 0.195 & 0.002 \\
\hline Education (centered) & 9.2 & 1 & 369 & 37.38 & 0.003 & 0.009 \\
\hline Target Race Counterbalance Order & 5.73 & 1 & 369 & 37.38 & 0.017 & 0.006 \\
\hline Target Race & 558.43 & 1 & 369 & 41.3 & $<.001$ & 0.379 \\
\hline Decade & 49.79 & 2.3 & 849.31 & 4.77 & $<.001$ & 0.014 \\
\hline Participant Race $\times$ Political Ideology & 1.89 & 2 & 369 & 37.38 & 0.152 & 0.004 \\
\hline Participant Race $\times$ Target Race & 50.41 & 1 & 369 & 41.3 & $<.001$ & 0.052 \\
\hline Political Ideology $\times$ Target Race & 4.81 & 2 & 369 & 41.3 & 0.009 & 0.01 \\
\hline Age $($ centered $) \times$ Target Race & 7.34 & 1 & 369 & 41.3 & 0.007 & 0.008 \\
\hline Education (centered) $\times$ Target Race & 4.44 & 1 & 369 & 41.3 & 0.036 & 0.005 \\
\hline Target Race Counterbalance Order $\times$ Target Race & 0.91 & 1 & 369 & 41.3 & 0.341 & 0.001 \\
\hline Participant Race $\times$ Decade & 1.64 & 2.3 & 849.31 & 4.77 & 0.191 & 0 \\
\hline Political Ideology $\times$ Decade & 0.63 & 4.6 & 849.31 & 4.77 & 0.66 & 0 \\
\hline Age $($ centered $) \times$ Decade & 1 & 2.3 & 849.31 & 4.77 & 0.377 & 0 \\
\hline Education $($ centered $) \times$ Decade & 0.5 & 2.3 & 849.31 & 4.77 & 0.635 & 0 \\
\hline Target Race Counterbalance Order $\times$ Decade & 3.35 & 2.3 & 849.31 & 4.77 & 0.029 & 0.001 \\
\hline Target Race $\times$ Decade & 109.23 & 2.23 & 823.38 & 5.7 & $<.001$ & 0.035 \\
\hline Participant Race $\times$ Political Ideology $\times$ Target Race & 1.05 & 2 & 369 & 41.3 & 0.35 & 0.002 \\
\hline Political Ideology $\times$ Target Race $\times$ Decade & 6.72 & 4.46 & 823.38 & 5.7 & $<.001$ & 0.005 \\
\hline Age $($ centered $) \times$ Target Race $\times$ Decade & 3.03 & 2.23 & 823.38 & 5.7 & 0.043 & 0.001 \\
\hline Education $($ centered $) \times$ Target Race $\times$ Decade & 2.35 & 2.23 & 823.38 & 5.7 & 0.089 & 0.001 \\
\hline Target Race Counterbalance Order $\times$ Target Race $\times$ Decade & 4.59 & 2.23 & 823.38 & 5.7 & 0.008 & 0.002 \\
\hline Participant Race $\times$ Political Ideology $\times$ Target Race $\times$ Decade & 3.63 & 4.46 & 823.38 & 5.7 & 0.004 & 0.002 \\
\hline
\end{tabular}

Note. Degrees of freedom are Greenhouse-Geisser (GG) corrected. $\eta^{2}{ }_{G}$ is generalized eta-squared, a measure of effect size. 
Table S5. Estimates of linear change in perceived discrimination across the decades in October 2019.

\begin{tabular}{|c|c|c|c|c|c|c|c|c|c|c|}
\hline & \multicolumn{5}{|c|}{ Black American Targets } & \multicolumn{5}{|c|}{ White American Targets } \\
\hline & estimate & $S E$ & $t$ & $d f$ & $p$ & estimate & $S E$ & $t$ & $d f$ & $p$ \\
\hline \multicolumn{11}{|c|}{ Black American Participants } \\
\hline liberal & -8.68 & 0.45 & -19.38 & 41366 & $<.001$ & 0.64 & 0.45 & 1.42 & 41366 & 0.16 \\
\hline moderate & -6.93 & 0.48 & -14.38 & 41366 & $<.001$ & -0.02 & 0.48 & -0.05 & 41366 & 0.96 \\
\hline conservative & -9.59 & 0.68 & -14.2 & 41366 & $<.001$ & 0.09 & 0.68 & 0.13 & 41366 & 0.9 \\
\hline \multicolumn{11}{|c|}{ White American Participants } \\
\hline liberal & -14.63 & 0.53 & -27.47 & 41366 & $<.001$ & 4.16 & 0.53 & 7.8 & 41366 & $<.001$ \\
\hline moderate & -18.12 & 0.51 & -35.34 & 41366 & $<.001$ & 7.18 & 0.51 & 14.01 & 41366 & $<.001$ \\
\hline conservative & -19.58 & 0.44 & -44.96 & 41366 & $<.001$ & 12.76 & 0.44 & 29.29 & 41366 & $<.001$ \\
\hline
\end{tabular}




\section{Current Sample (October 2019)}

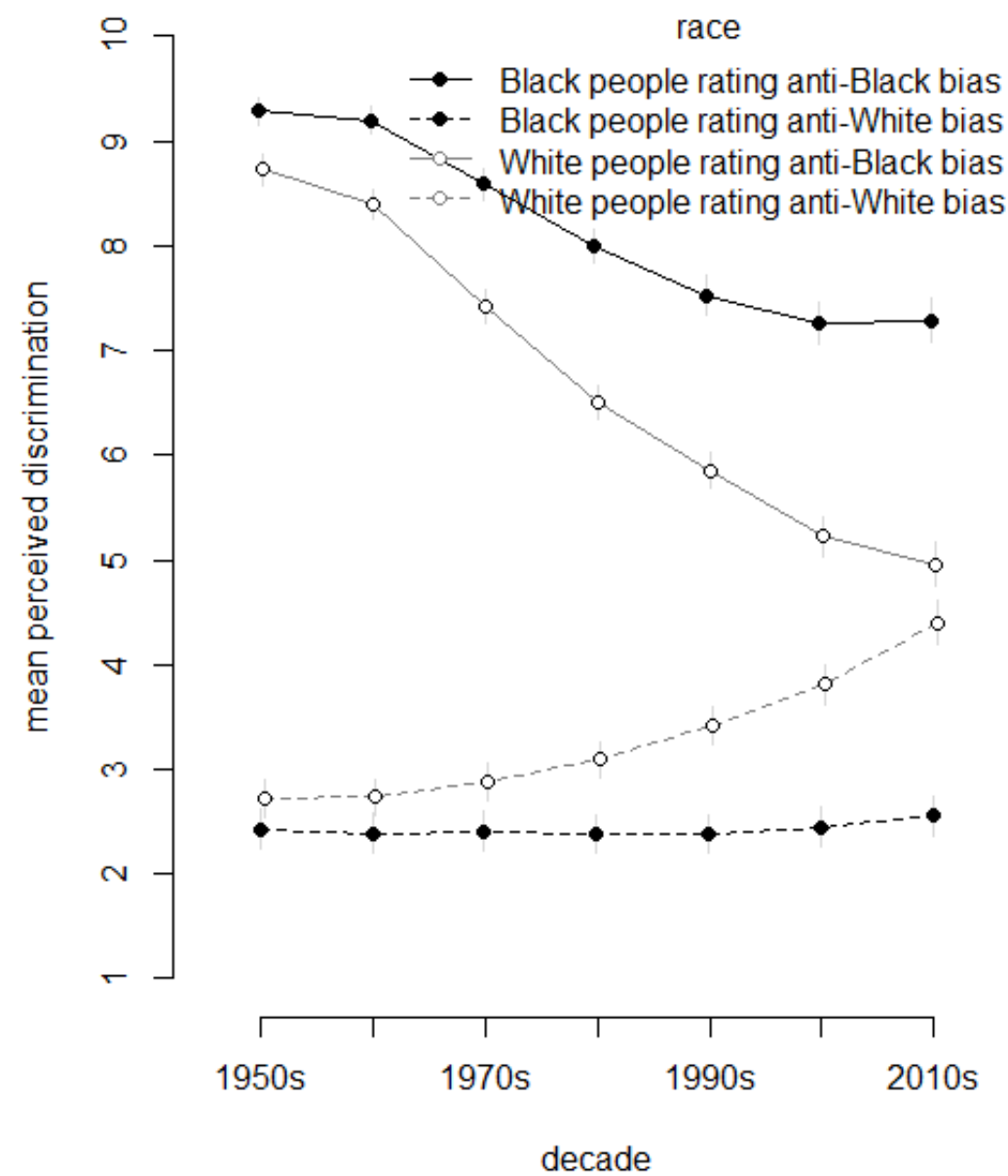

\section{Current Sample (October 2019)}

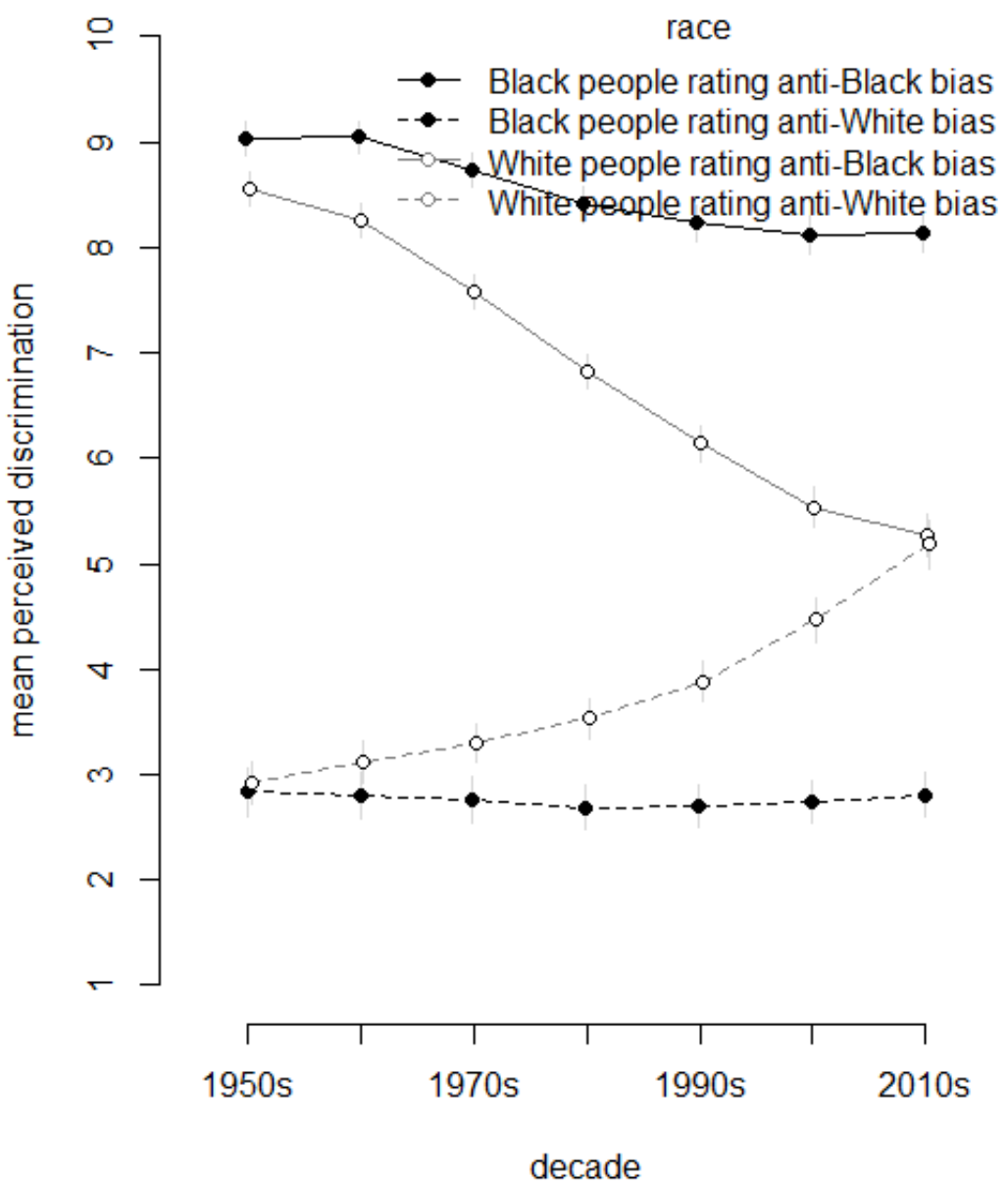

Figure S3. Discrimination against Black targets (solid lines) and White targets (dashed lines) perceived by Black participants (black lines with filled black circles) and White participants (gray lines with empty gray circles) by decade in October 2019. The panel on the left shows results for participants who rated Black American targets first. The panel on the right shows results for participants who rated White American targets first. Error bars reflect $95 \%$ confidence intervals. 


\section{Author Contributions Based on the Contributor Roles Taxonomy (CRediT;}

\section{https://casrai.org/credit)}

Conceptualization: Raea Rasmussen, David E. Levari, Muna Akhtar, Chelsea S. Crittle, Megan

Gately, Jeremy Pagan, Andrea Brennen, Dylan Cashman, Alia N. Wulff, Michael I. Norton,

Samuel R. Sommers, and Heather L. Urry.

Data Curation: Heather L. Urry.

Formal Analysis: Heather L. Urry.

Funding Acquisition: Michael I. Norton and Heather L. Urry.

Investigation: David E. Levari and Heather L. Urry.

Methodology: Raea Rasmussen, David E. Levari, Muna Akhtar, Chelsea S. Crittle, Megan

Gately, Jeremy Pagan, Andrea Brennen, Dylan Cashman, Alia N. Wulff, Michael I. Norton,

Samuel R. Sommers, and Heather L. Urry.

Project Administration: David E. Levari and Heather L. Urry.

Resources: David E. Levari and Heather L. Urry.

Software: David E. Levari and Heather L. Urry.

Supervision: Heather L. Urry.

Validation: Heather L. Urry.

Visualization: Raea Rasmussen, Dylan Cashman, and Heather L. Urry.

Writing - Original Draft Preparation: Raea Rasmussen, Muna Akhtar, Chelsea S. Crittle, Megan Gately, and Jeremy Pagan.

Writing - Review \& Editing: Raea Rasmussen, David E. Levari, Muna Akhtar, Chelsea S.

Crittle, Megan Gately, Jeremy Pagan, Andrea Brennen, Dylan Cashman, Alia N. Wulff, Michael

I. Norton, Samuel R. Sommers, and Heather L. Urry. 